\title{
“É UM PROBLEMA \\ DE TODO MUNDO": \\ CONCEITOS, \\ MÉTODOS E PRÁTICAS \\ NO ENSINO \\ DE PORTUGUÊS \\ PARA REFUGIADOS
}

\section{"ES UN PROBLEMA DE TODO EL MUNDO": CONCEPTOS, MÉTODOS Y PRÁCTICAS EN LA ENSEÑANZA DE PORTUGUÉS PARA REFUGIADOS}

"IT IS A PROBLEM FOR EVERYONE": CONCEPTS, METHODS AND PRACTICES IN TEACHING PORTUGUESE FOR REFUGEES

Bruno Deusdará*

Poliana Coeli Costa Arantes** Ana Karina Brenner***

Universidade do Estado do Rio de Janeiro

RESUMO: Neste artigo, problematizamos a rede conceitual e metodológica que sustenta nossas práticas de acolhimento a refugiados. A partir dos pressupostos teóricos, iniciamos produção de material didático próprio e supervisão das aulas ministradas por voluntários. Foi constituída uma equipe multidisciplinar e interinstitucional que tem problematizado as implicações

\footnotetext{
*Professor Adjunto de Linguística e da Pós-graduação em Letras e em Letras e Linguística UERJ. Bolsista dos Programas Jovem Cientista do Nosso Estado (FAPERJ) e Prociência (UERJ/FAPERJ). Pesquisador da Cátedra Sérgio Vieira de Mello (ACNUR/ONU)naUERJ. E-mail: brunodeusdara@gmail.com.

** Professora Adjunta de Língua e Literatura Alemã e da Pós-graduaça em Letras da UERJ. Bolsista do Programa Prociência (UERJ/FAPERJ). Coordenadora da Cátedra Sérgio Vieira de Mello (ACNUR/ONU) na UERJ. VicecoordenadoradoGT/ANPOLL Linguagem, Enunciaçãoe Trabalho. E-mail: polianacoeli@yahoo.com.br.

*** Professora Adjunta de Educação de Jovens e Adultos e da Pós-graduação em Educação (ProPEd). Pesquisadora do Observatório Jovem do Rio de Janeiro e da Cátedra Sérgio Vieira de Mello (ACNUR/ONU) na UERJ. E-mail: anakbrenner10@gmail.com
} 
conceituais, éticas e políticas do professor de línguas que atua na acolhida a refugiados. O objetivo da criação da equipe é garantir o espaço de discussão em torno da demanda concreta de atuação, supervisão da elaboração de materiais e avaliação permanente da aplicação do material e das demais ações relativas ao curso. A noção de direitos e garantia de acesso aos serviços públicos que os asseguram, a não linearidade de conteúdos, a participação ativa dos refugiados e professores voluntários no apontamento dos temas e conteúdos do material didático e das aulas constituem eixos fundamentais de nossa prática.

PALAVRAS-CHAVE: Ensino de Línguas para refugiados. Refúgio. Direitos Humanos.

RESUMEN: En este artículo, problematizamos la red conceptual y metodológica que sustentan nuestras prácticas de acogida a refugiados. A partir de los presupuestos teóricos se inició la producción de material didáctico propio y supervisión de las clases impartidas por voluntarios. El equipo multidisciplinario e interinstitucional fue constituido y ha problematizado las implicaciones conceptuales, éticas y políticas del profesor de lenguas que actúa en la acogida a refugiados. Nuestro objetivo con la creación del equipo es garantizar el espacio de discusión en torno a la demanda concreta de actuación, supervisión de la elaboración de materiales y evaluación permanente de la aplicación del material y de las demás acciones relativas al curso. La noción de derechos y garantía de acceso a los servicios públicos que los aseguran, la no linealidad de contenidos, la participación activa de los refugiados y profesores voluntarios en el apunte de los temas y contenidos del material didáctico y de las clases constituyen ejes fundamentales de nuestra práctica.

PALABRAS CLAVE: Enseñanza de idiomas para refugiados. Refugio. Derechos humanos.

ABSTRACT: In this article, we discuss the conceptual and methodological network that support our refugee reception practices. Based on the theoretical assumptions, we started making our own teaching material and supervising classes given by volunteers. A multidisciplinary and inter-institutional team was formed to question the conceptual, ethical and political implications of the language teacher who works in the reception of refugees. The team was set up to guaranteeing discussion about concrete demand for actions, supervision of the preparation of materials and ongoing evaluation of the use of the material and other course-related actions. The notion of rights and the assurance of access to public services that guarantee such rights, the non-linearity of content, the active participation of refugees and volunteering teachers in indicating topics and contents as teaching material and classes were the crucial axes of our practice.

KEYWORDS: Language teaching for refugees. Refuge. Human Rights.

\section{CONSIDERAÇÕES INICIAIS}

"Eu acredito que o que acontece no Congo não é um problema só do Congo, é um problema de todo mundo”. Iniciamos nosso artigo com o enunciado proferido por uma profissional das Relações Internacionais, refugiada da República Democrática do Congo no Brasil, em evento recente, realizado pelo Instituto de Medicina Social (IMS), da Universidade do Estado do Rio de Janeiro (UERJ). Destacamos esse enunciado da palestra proferida no evento por razões diversas. Entre elas, a possibilidade que nos oferece de acessar o campo de forças no qual estamos implicados e sobre o qual vimos refletindo, desde que iniciamos nosso trabalho de supervisão do curso de Português para refugiados, promovido pela Cáritas-RJ, em parceria com a UERJ.

Neste artigo, problematizamos a rede conceitual e metodológica que vem sustentando nossas práticas de acolhimento a refugiados, considerando as ações de supervisão e elaboração de material didático, empreendidas por uma equipe multidisciplinar. Desejamos especialmente refletir sobre sentidos e valores presentes nas práticas e políticas de acolhimento, viabilizando uma crítica à visão hegemônica no discurso midiático que aponta para uma concepção hierarquizante e assistencialista das ações.

Nessa trajetória, contamos com equipe composta por: professores dos cursos de Letras e Pedagogia; pedagoga, responsável pela coordenação acadêmica; professores voluntários, com formações profissionais diversas e estudantes de Graduação, bolsistas dos projetos de extensão elaborados para formalizar a iniciativa. Essa equipe multidisciplinar se formou para garantir o espaço de discussão em torno da demanda concreta de atuação, supervisão da elaboração de materiais e avaliação permanente da aplicação do material e das demais ações relativas ao curso de português. 
Com efeito, a solicitação de atuação que nos foi inicialmente dirigida, como professores da área de educação de jovens e adultos e da área de ensino de línguas, já comportava tanto uma necessidade de superar as limitações de um material didático dirigido genericamente a estrangeiros, quanto o imperativo de acolhida e integração social, cultural, econômica e afetiva de pessoas que se deslocam de seus países e chegam ao Rio de Janeiro pelos fluxos de migração forçada. Dito de outro modo, o perfil de falante estrangeiro que se observava predominantemente subjacente aos textos de leitura e exercícios propostos no material não correspondia às necessidades básicas dos primeiros momentos do acolhimento.

Nessas circunstâncias, ressaltamos a caracterização do contexto como um processo complexo que não se reduz à mera exposição de dados e informações de eventos independentes e exteriores. Sem dúvida, os dados fornecidos pelos órgãos oficiais já inscrevem o contemporâneo na maior crise migratória, ultrapassando os contornos da 2a Grande Guerra. Atualmente, mais de 65 milhões de pessoas (ACNUR, 2016) encontram-se na condição de refugiadas, requerentes de refúgio ou deslocadas dentro de seus países “[...] temendo ser perseguido por motivos de raça, religião, nacionalidade, grupo social ou opiniões políticas [...]” (ONU, 1951). A expressiva maioria (40,8 milhões) é de deslocados internos, ou seja, impossibilitados, por razões de segurança, de continuar em suas casas, também não encontram condições de atravessar fronteiras em busca de melhores condições de vida. Dos que conseguem sair de seus países, a maioria permanece em países vizinhos. Ou seja, a chamada "crise dos refugiados", que é apresentada na grande imprensa pelo fluxo de refugiados rumo a países europeus, é apenas a ponta de um iceberg que mantém invisíveis milhões de pessoas deslocadas de seus lares e fixadas precariamente, por vezes clandestinamente, em condições subumanas, nas "franjas" dos conflitos civil-militares que afetam notadamente o continente africano e o Oriente Médio, em alguns países, há mais de 30 anos. Segundo dados do ACNUR (2016), em 2016, 51\% dos refugiados são crianças, 46\% adultos e 3\% idosos.

Dada a singularidade da experiência, proporemos a inversão da sequência convencional teoria-método-análise, iniciando nossa discussão pela caracterização do campo no qual temos atuado. Em seguida, apresentamos as ferramentas conceituais que temos adotado em nossas atividades, explicitando sua natureza interdisciplinar na promoção de pontos de convergência entre referenciais do campo dos estudos do discurso, da educação de jovens e adultos e do acolhimento em saúde. A nosso ver, o tipo de trabalho de acolhimento que realizamos investe em uma perspectiva micropolítica, segundo a qual "[...] a condição de refugiado não remete apenas ao outro que se deseja incluir. A inclusão do refugiado remete a uma rede de assistência social não plenamente assegurada a todos [...]" (ARANTES; DEUSDARÁ; BRENNER, 2016, p. 1200). Por fim, discutimos alguns dos eixos de trabalho que foram elaborados a partir dos encontros e reflexões conjuntas, ressaltando as implicações conceituais, éticas e políticas do professor de línguas que atua na acolhida a refugiados.

Por esse percurso, entendemos que este artigo pode contribuir para ressaltar a complexidade do campo de estudos e ações no ensino de línguas, afirmando a singularidade do trabalho com refugiados. Essa singularidade se caracteriza justamente pela primazia de reflexão crítica a respeito das práticas e políticas de acolhida frente aos métodos e aos conceitos que sustentarão o trabalho a ser desenvolvido.

\section{O CONTEXTO BRASILEIRO DE ACOLHIMENTO A REFUGIADOS: GARANTIAS JURÍDICAS E REDES DE ASSISTÊNCIA}

Nesta seção, procuramos apresentar o ordenamento jurídico que viabiliza as práticas de acolhimento no Brasil, bem como suas implicações políticas na articulação com as redes de assistência nas quais se veem enredados os profissionais envolvidos com o grupo de refugiados. Desse modo, apresentamos inicialmente algumas questões básicas a respeito das condições legais de acolhimento e também da inserção particular que o profissional que atua com o grupo de refugiados passa a ter, intentando dialogar com o seguinte problema, antecipando elementos de ordem macropolítica:

O ensino de uma língua de acolhimento a jovens e adultos refugiados ou solicitantes de refúgio apresenta especificidades que não são as mesmas do ensino de língua estrangeira, seja por considerar de maneira excessivamente genérica essa condição de "estrangeiro", seja por perceber um apagamento dessa inscrição 
multifacetada do refugiado, no país de acolhida, atravessada por tensões de diferentes ordens. (ARANTES; DEUSDARÁ; BRENNER, 2016, p. 1202)

Como maneira de reforçar a argumentação no sentido da impossibilidade de postular essa condição de refugiado apenas como um grupo específico de "estrangeiros", recuperamos agora uma caracterização da rede institucional mobilizada nas práticas e políticas de integração.

É através de rede de instituições sociais conveniadas com o Ministério da Justiça que ocorre o acolhimento a refugiados no Brasil, seguindo orientações de normativas nacionais e internacionais, das quais o Brasil é signatário, e também dos representantes do ACNUR - Alto Comissariado das Nações Unidas para Refugiados - no país.

Nesse contexto, o órgão responsável por receber e analisar os pedidos de refúgio e elaborar ou articular políticas já existentes para a acolhida e atenção aos solicitantes de refúgio e aos refugiados é o CONARE - Comitê Nacional para os Refugiados. Em sua composição, têm assento representantes dos Ministérios da Justiça, das Relações Exteriores, do Trabalho e Emprego, da Saúde e da Educação além do Departamento da Polícia Federal; integram, ainda, o comitê, um representante de organização não governamental que se dedique a oferecer atendimento e proteção a refugiados (atualmente a Cáritas Arquidiocesana ocupa esta vaga) e um representante do ACNUR - este último com direito a voz, mas sem direito a voto.

Dados do próprio CONARE (BRASIL, 2016) indicam que o número de refugiados reconhecidos pelo país cresceu $127 \%$ entre 2010 e 2016, e que a maior parte deles tem idades entre 18 e 59 anos. São, hoje, 8.863 refugiados no Brasil (BRASIL, 2016), de 79 nacionalidades. O maior número de reconhecimentos envolve sírios, angolanos, colombianos, congolenses, libaneses, iraquianos, liberianos, paquistaneses e leoneses. São Paulo possui 2 centros de acolhimento para refugiados, com capacidade para 415 pessoas. Há planos de implantação de outros centros deste tipo em Porto Alegre e Florianópolis. Já o Rio de Janeiro não tem estrutura pública similar, conta apenas com alojamentos improvisados em paróquias e igrejas, sem apoio oficial do estado.

Além do aumento no contingente de reconhecidos, o CONARE registrou forte expansão nas solicitações de refúgio (BRASIL, 2016). Nos últimos cinco anos, esses pedidos subiram 2.868\%, passando de 966, em 2010, para 28.670, em 2016. O crescimento é diretamente ligado ao conflito armado na Síria, mas também ao persistente e reiterado conflito político em que mergulha a República Democrática do Congo, uma guerra civil que já dura mais de 30 anos. No Rio de Janeiro, os anos de eleições no Congo marcam aumento no fluxo de congoleses que buscam refúgio na cidade e/ou região.

As leis e regulamentações brasileiras garantem ao refugiado ou solicitante de refúgio plenos direitos sociais, inclusive o direito imediato ao trabalho. Relatos de refugiados atendidos pela Cáritas e de participantes de diferentes eventos festivos e acadêmicos são reiterativos da importância deste direito: o trabalho assegura a possibilidade de realizar tarefa produtiva, buscar reinserção profissional dando novos sentidos a vidas devastadas pelas violências vividas em territórios de guerra e ainda permite o sustento autônomo de si mesmo e da família, quando é o caso. Poucos são os países que permitem que solicitantes de refúgio, a quem ainda não se concedeu o direito de permanecer no país, tenham direito de buscar trabalho. Esta é uma marca positiva da política de refúgio no Brasil.

Nosso país possui amplo e abrangente arcabouço jurídico-institucional para assegurar aos cidadãos nascidos e aos acolhidos - por migração ou deslocamentos forçados - direitos sociais. Nossa Constituição Federal, promulgada em 1988, estabelece que é um de seus objetivos fundamentais "[...] promover o bem de todos, sem preconceitos de origem, raça, sexo, cor, idade e quaisquer outras formas de discriminação [...]" (BRASIL, 1988, art. 3º inciso IV). O art. $6^{\circ}$ estabelece que "[...] são direitos sociais a educação, a saúde, a alimentação, o trabalho, a moradia, o transporte, o lazer, a segurança, a previdência social, a proteção à maternidade e à infância, a assistência aos desamparados, na forma desta Constituição [...]". Da definição sobre o que são os direitos sociais, derivaram leis complementares como o Estatuto da Criança e do Adolescente - ECA (Lei 8069/90), a Lei Orgânica da Assistência Social - LOAS (Lei 8742/93) e a Lei de Diretrizes e Bases da Educação Nacional - LDBEN (Lei 9394/96). Elas estabelecem princípios norteadores, diretrizes e ações necessárias para a garantia dos direitos de crianças e adolescentes, para as políticas de assistência social e para a educação nacional, respectivamente.

Deusdará, Arantes \& Brenner| "É um problema de todo mundo": conceitos, métodos e práticas no ensino... 
A lei 9.474/97 é conhecida como "Lei do Refúgio" e garante que o refugiado terá direito, nos termos da Convenção sobre o Estatuto dos Refugiados de 1951, à cédula de identidade comprobatória de sua condição jurídica, carteira de trabalho e documento de viagem (BRASIL, 1997, art. 6º ). E é pela posse de cédula de identidade e de carteira de trabalho que também se assegura acesso ao sistema de saúde, às escolas públicas e aos demais serviços que asseguram (ou devem assegurar) os direitos básicos de todos os cidadãos e residentes.

Neste ponto coloca-se, novamente, a questão trazida à baila pela palestrante congolesa. Se, por um lado, pergunta-se se o que acontece no Congo é problema só do Congo ou de todos, por outro, o atendimento e a garantia aos direitos dos refugiados passam justamente pela garantia de direitos e políticas públicas adequadas a todos os cidadãos brasileiros. A luta para que nosso país acolha bem e adequadamente os refugiados e solicitantes de refúgio é, portanto, a luta histórica pela garantia das políticas públicas de saúde, educação, moradia, transporte, emprego e renda, entre outras. A inclusão dos refugiados e solicitantes de refúgio, em programas, projetos, ações públicas, nos faz reconhecer a rede de proteção social que foi conquistada nas últimas décadas no país e também reconhecer as ainda persistentes fragilidades dos diversos sistemas (de saúde, educação, assistência social, por exemplo) que precisam ser superadas. A ação de inclusão demanda atenção a princípios que passam pelo direito à saúde, à universalidade do acesso aos bens de saúde e educação, à equidade das ofertas desses bens, à integralidade do sistema de cuidado e à participação cidadã, à solidariedade, à cooperação, à justiça e à não discriminação. E todos esses são princípios norteadores das lutas históricas de movimentos sociais, fóruns da sociedade civil, militantes, pesquisadores e ativistas de muitas áreas pela diminuição das desigualdades sociais e pela construção de uma sociedade mais justa e democrática no Brasil.

Como se vê, a discussão proposta neste item ressalta não apenas a impossibilidade de se postular o refugiado como um tipo específico de "estrangeiro", como se propõe a avançar no sentido de evidenciar e fornecer elementos para a atuação profissional com o grupo de refugiados. Desse modo, parece-nos pertinente apresentar ainda um modo de conceber a inclusão. Tal concepção nos permite transitar do plano macropolítico das categorizações previstas na forma da lei e das redes institucionais estatais ao plano micropolítico, onde a vida concreta habita as intensidades e (re)elabora e atualiza de modo sempre singular as categorias jurídicoestatais.

Com efeito, o desafio colocado a quem se propõe a atuar na integração dos refugiados nos convoca a ultrapassar o senso comum, segundo o qual a inclusão se daria pela incorporação da diferença em uma ordem dada (pensada então como identitária). Quando consideramos as lutas pela ampliação das redes de assistência a refugiados como parte das lutas pela ampliação da assistência a todos, consideramos assim que a sua presença não nos fornece indicadores e pistas que remetem apenas ao outro (concebido assim como "diferente de mim"). Preferimos, por outro caminho, dialogar com a perspectiva de inclusão, tal como elaborada a seguir:

Inclusão, na perspectiva democrática, significa acolher e incluir as diferenças, colocando a diversidade lado a lado. Diversidade da manifestação do vivo, da heterogeneidade e das singularidades do humano. Incluir o outro, aquele que não sou eu, que de mim estranha, e que em mim produz estranhamento, provocando tanto o contentamento e a alegria, como mal-estar. A inclusão produz, portanto, a emergência de movimentos ambíguos e contraditórios, os quais devem ser sustentados por práticas de gestão que suportem o convívio da diferença e a partir dela sejam capazes de produzir o comum, que pode ser traduzido como projeto coletivo. (PASCHE; PASSOS, 2010, p. 426)

Essa perspectiva a respeito da inclusão nos convoca a interrogar sobre as rotinas e hábitos de sala de aula nos lançando no desafio de deslocarmos o direcionamento de nossas práticas de modo mais flexível. No próximo item, pretendemos caracterizar as polêmicas subjacentes às práticas de acolhimento a refugiados. 


\section{3 “CRISE DOS REFUGIADOS” OU “CRISE HUMANITÁRIA”: PISTAS PARA A CONTEXTUALIZAÇÃO DOS IMPASSES E DESAFIOS NO TRABALHO COM REFUGIADOS}

Iniciamos este item recuperando a fala da palestrante congolesa: "Eu acredito que o que acontece no Congo não é um problema só do Congo, é um problema de todo mundo". Entre relatos de episódios de horror da guerra e seus efeitos devastadores sobre os grupos familiares, emerge um enunciado que inscreve explicitamente um ponto de vista assumido pela enunciadora. A potência desse enunciado parece residir justamente em seu movimento múltiplo de fazer irromper uma opinião, de ressignificar os relatos apresentados, de se dirigir ao público ouvinte, enredando-o nas tramas do acolhimento.

Considerando ser necessário oferecer ao leitor uma breve contextualização, indicamos que o relato da palestrante procurava situar as razões que a conduziram à migração forçada, partindo de uma caracterização de sua atuação profissional no acolhimento oficial a pessoas em situação de vulnerabilidade e contrastando com as sucessivas notícias dos horrores da guerra, com especial ênfase para os efeitos devastadores da violência física e sexual em invasões aos espaços domésticos.

Em sua narrativa, foram destacados episódios, técnicas e impressões que remetem, à primeira vista, a uma experiência histórica particular - aquela enfrentada pela população civil de uma determinada nacionalidade, nos últimos vinte anos. A duração no tempo desse conflito bélico já ressalta a gravidade da situação referida. Para se dar corpo à situação, basta imaginar que os jovens daquele país apenas o conhecem como cenário de violações extremadas dos direitos básicos e de todas as formas de expressão de dignidade da vida humana.

Durante o relato, um primeiro efeito provocado nos ouvintes pode ter sido o do afastamento: "fala-se diante de mim de uma realidade que não é a minha”. Por esse efeito, o outro pode emergir como figuração que se inscreveria no distanciamento, tanto pelas dimensões geográficas quanto pelos horrores aparentemente não experimentados. Nesse efeito, o encontro com a alteridade talvez pudesse se inscrever como remetendo à ordem do contato com uma experiência de vida bastante distinta da minha, em outras palavras, uma alteridade que se pudesse definir como "não eu", a quem eu pudesse dirigir afetos de tristeza, solidariedade e indignação. Nesses termos, o encontro com a alteridade se expressaria por afetos movidos por um grau maior de passividade, destacando simultaneamente algo que eu dirigiria ao outro e algo em relação ao qual minha possibilidade de ação pudesse ser concebida como restrita.

Esse talvez tenha sido, no entanto, apenas um dos diversos efeitos possíveis provocados no público ouvinte. Como se vê, o enunciado destacado parece oferecer uma articulação importante: escavando a tristeza e o horror dos dramas cotidianos dos congoleses, no contexto de devastadora guerra civil, a palestrante pinça delicadamente um fio que nos implica a todos.

Nesse momento, a tessitura dos dramas deixa ver as tramas que lhe dão sustentação e que nos envolvem a todos. O atual conflito bélico na República Democrática do Congo possui motivação fortemente econômica: trata-se de disputa pela exploração de ouro, diamante e coltan (uma combinação dos minérios columbita e tantalita), utilizado na produção de equipamentos eletrônicos como celulares e tablets. Já não é mais apenas pela solidariedade humanitária que nos assumimos implicados com a narrativa construída na palestra. Agora somos também convocados como consumidores dos equipamentos eletrônicos mencionados, cuja origem - as aflições e danos irreparáveis que a trajetória de sua produção impõe-parecemos ignorar.

Desse ponto de vista, a narrativa é percebida como ato que nos convoca a habitar um campo de forças, em sua dimensão paradoxal:

A potência do ato narrativo consiste em gerar significações capazes de entretecer novos afetos, esperanças, transgressões e elaborações. Não nega a perda e o sofrer - constituintes da condição humana - mas se depara com eles, posto que narrar permite encontrar outros movimentos com os fios da trama vivida. (DUARTE, 2015, p. 134)

A força do ato de narrar se desloca entre sofrimentos, dores, denúncias e a convocação em direção aos ouvintes. A força do narrar ganha materialidade nas polêmicas que se inscrevem no enunciado. Vejamos como esse conjunto de forças explicitado 
anteriormente se expressa igualmente no enunciado destacado, no início deste artigo. Incapazes de reproduzir no impresso a força com que fora originalmente proferido, recuperamos sua materialidade para circunscrever uma polêmica que nele se sugere. Em uma abordagem discursiva das práticas de linguagem, reconhecemos na negação de natureza polêmica ${ }^{1}$ a capacidade de nos remeter facilmente a um ponto de vista afirmativo subjacente, qual seja, "o que acontece no Congo é um problema só do Congo" (ponto de vista 1). Em contraposição a esse ponto de vista, teríamos outro, que pode ser apreendido tanto no enunciado marcado pela negação "o que acontece no Congo não é um problema só do Congo", quanto em outro, que é apresentado em justaposição "[o que acontece no Congo] é um problema de todo mundo". Ambos os enunciados são assumidos como correspondentes de um mesmo ponto de vista (ponto de vista 2).

Com efeito, o ponto de vista 1 (PV1) parece pôr em cena um enunciador nacionalista, cujo ponto de vista se caracterizaria por uma consideração prévia e determinante das fronteiras nacionais. Tal PV1, que se caracteriza pela assunção prévia das fronteiras dos estados nacionais frente a qualquer demanda humanitária supranacional, parece encontrar ressonância em manchetes diversas da imprensa brasileira.

Apenas a título de ilustração, recuperamos duas manchetes recentes a respeito da desativação do campo de refugiados em Calais, na França: "França começa a transferir 1.500 crianças e jovens do campo de Calais" (FRANÇA..., 2016); "Após fechamento de campo em Calais, crianças refugiadas ficam sem abrigo" (APÓS..., 2016). Nessas manchetes, o elemento "França" é personificado e age sobre "1.500 crianças e jovens". Mesmo já estando em território francês, sugere-se serem as "1.500 crianças e jovens" que ainda mantêm a marca do estrangeiro, passivos diante das ações de transferência. Na manchete seguinte, a designação "crianças refugiadas" já apresenta explicitamente a marca da especificação. Não são apenas "crianças", mas "crianças refugiadas", em relação às quais outros implícitos parecem emergir. A ausência do elemento "refugiadas" em "crianças ficam sem abrigo", podem ativar subentendidos de outra ordem, gerando outras implicações no leitor. Provavelmente, o grau de responsabilidade pode ser compreendido como distinto em relação aos dois grupos, na compreensão atribuída ao PV1, que afirmaria, segundo análise acima, que "o que acontece no Congo é um problema só do Congo".

Outro exemplo de enunciados que podem ser atribuídos a esse enunciador-nacionalista é encontrado em uma postagem cujo propósito é bastante específico: apresentar temas definidos como "atualidade" a estudantes em preparação para os exames vestibulares das Universidades. Destacamos, a seguir, um parágrafo de um curto texto, que trata da "Assimilação da massa de imigrantes pelo Estado":

O fato é que as decisões de cada país europeu em aceitar ou não os refugiados geram uma crise de teor ético e político ao mesmo tempo. Muitas são as indagações levantadas por especialistas que acompanham esse fluxo migratório. Uma delas diz respeito à capacidade de países em plena crise econômica, como a Grécia, de acomodar, dar emprego e assistência social a milhares de refugiados. (FERNANDES, 2016)

Na primeira frase, a perspectiva posta em cena é a de "cada país europeu”, que pode "aceitar ou não os refugiados". Na segunda frase, a expressão "os refugiados" é associada a "esse fluxo migratório". Na terceira frase, apresenta-se finalmente a "crise de teor ético e político", mencionada na primeira frase: "diz respeito à capacidade de países em plena crise econômica, como a Grécia, de acomodar, dar emprego e assistência social a milhares de refugiados". Desse modo, o que se constrói nesse parágrafo é uma argumentação que parece encontrar ressonância no PV1, quando o que permanece em tela é justamente a preocupação em torno da "assimilação dos refugiados", ignorando-se a perspectiva das próprias pessoas que, por grave ameaça à sobrevivência e dignidade, são forçadas a migrar de seus países.

Restituindo os termos da polêmica inicialmente apresentada neste item, acrescentaríamos que o PV2, que se caracteriza pela possibilidade de articulação dos enunciados “o que acontece no Congo não é um problema só do Congo" e "[o que acontece no

${ }^{1}$ A respeito do fenômeno da negação polêmica, ver Ducrot (1987). 
Congo] é um problema de todo mundo", encontra forte ressonância em reflexões como as que vêm empreendendo autores como Agamben (2002) e Butler (2009).

A título de ilustração, recuperamos a seguir trechos de cada um desses autores, que parecem sustentar o PV2, como um enunciador que optamos por chamar de "humanitário-internacionalista", visto que o que se sustenta toma por base a condição humanitária como precedente a qualquer delimitação nacional. Ao contrário, as circunstâncias implicadas nos fluxos de migração forçada chegam mesmo a interrogar as promessas fundantes dos estados nacionais.

Vejamos o que diz Butler a respeito dos efeitos das atividades bélicas na seletividade dos sentidos para apreender os eventos e suas condições de produção:

A guerra sustenta suas práticas atuando sobre os sentidos, fazendo-os apreender o mundo de modo seletivo, atenuando a comoção diante de determinadas imagens e determinados sons, e intensificando as reações afetivas aos outros. É por isso que a guerra atua minando as bases de uma democracia sensata, restringindo o que podemos sentir, fazendo-nos sentir repulsa ou indignação diante de uma expressão de violência e a reagir com justificada indiferença diante de outra. (BUTLER, 2009, p. 83)

De acordo com a autora, as práticas de guerra produzem modulações nas maneiras de perceber e sentir a realidade, que podem conduzir ao estabelecimento do vínculo com o outro sustentado na indiferença. Diante de tais modulações e dos riscos que a indiferença oferece à democracia, a autora propõe que se assuma como princípio a precariedade da existência humana como possibilidade de agregação.

Embora nem todas as formas de precariedade sejam produzidas por arranjos políticos e sociais, continua sendo uma tarefa da política minimizar a condição de precariedade de forma igualitária. A guerra é precisamente um esforço para minimizar a precariedade de alguns e maximizá-la para outros. (BUTLER, 2009, p. 86)

Com efeito, o reconhecimento da precariedade como condição humana generalizada - ainda que nem toda forma de precariedade seja efetuada por vetores político-sociais - pode ser um princípio potente em direção à alteridade. Tal princípio, proposto pela autora, parece inverter o que habitualmente se institui, nas práticas de acolhimento, quando, na possibilidade de agir em direção ao outro, me percebo em condições "melhores". Na concepção apresentada acima, o vínculo se constrói a partir do reconhecimento da precariedade generalizada e ganha força justamente no sentido de, por aí, agir com o propósito de minimizar tal condição, de maneira igualitária.

De outro modo, a perspectiva sustentada por Agamben (2002) relaciona o crescente fluxo migratório forçado ao projeto de estado moderno:

Se os refugiados (cujo número nunca parou de crescer no nosso século [o século xx], até incluir hoje uma porção não desprezível da humanidade) representam, no ordenamento do Estado-nação moderno, um elemento tão inquietante, é antes de tudo porque, rompendo a continuidade entre homem e cidadão, entre nascimento e nacionalidade, eles põem em crise a ficção originária da soberania moderna. (AGAMBEN, 2002, p. 138)

Como se vê, para o autor, a intensificação dos quantitativos de refugiados interroga o que ele chama de "a ficção originária da soberania moderna", sugerindo que tal ficção teria entre suas bases a continuidade entre nascimento e nacionalidade. Em outros termos, é a relação entre a dimensão biológica da vida (nascimento) e sua inscrição na ordem política (nacionalidade) que se apresenta fraturada. Um exemplo de tal fragmentação se pôde constatar anteriormente, quando recuperamos as manchetes acerca da desativação do campo de refugiados em Calais, na França. A ação do governo sobre os indivíduos passa assim também pelo crivo da nacionalidade. 
realidades, que abre o atual à pluralidade das formas de existência e qualifica a transformação enquanto criação de possíveis. (ROCHA; AGUIAR, 2003, p. 70)

Optamos por percorrer os elementos intensivos presentes na narrativa de quem vivencia o processo, procurando habitar o modo como se constrói o relato e como se cria uma experiência de ultrapassagem do horror em direção ao outro. Desejamos, desse modo, colocar em suspenso, ainda que provisoriamente, a delimitação entre ensino de português como língua materna e como língua estrangeira, para facultar a emergência de outras questões.

\section{DESAFIOS PARA O ENSINO DE PORTUGUÊS COM REFUGIADOS}

Nesta seção, discutiremos questões que se mostraram fundamentais na elaboração da proposta de trabalho de acolhimento a refugiados, compreendendo sua emergência como aspecto definidor da singularidade desse tipo de trabalho em relação àquele desenvolvido com "estrangeiros". Destinamos esta parte do artigo à discussão de eixos para o ensino de língua com refugiados, partindo de nossa experiência com o curso de extensão "Português para refugiados", cadastrado no Departamento de Extensão da UERJ.

Recebemos mais de 250 alunos por semestre e em fluxo contínuo e, atualmente, o número de mulheres refugiadas tem alterado a composição das turmas, que há um tempo era majoritariamente masculina. A população feminina no curso representa hoje $50 \%$ do total de alunos e esse cenário tem nos apontado necessidades, caminhos e demandas bastante distintos, até porque as mulheres estão inseridas em situações, muitas vezes, mais vulneráveis que a dos homens e, em sua maioria, assumem a responsabilidade com os filhos, o que acarreta necessidades de comunicação com a língua que tem a ver com situações cotidianas, tais como matricular seus filhos na escola, levar as crianças ao médico, levar os filhos para atividades de lazer na cidade, utilizar o transporte público e a rede pública de saúde. Como se pode observar, o curso nos oferece um campo permanente de questões e desafios a serem problematizados. Tal modo de acolher as questões nos insere em uma proposta de intervenção institucional: "Não esqueçamos que intervenção é "estar entre" e "assistir", portanto, vincula uma dimensão ética que, por intermédio de atos de cuidado, possibilita apoio no desenrolar da trama institucional. Estar entre e assistir é pensar com o outro, e não pelo outro, para o outro, sobre o outro, sob o outro.” (DUARTE, 2015, p. 142).

A proposta de curso de português para refugiados conduzida pela Cáritas através da parceria com a UERJ baseia-se fortemente na ideia de acolhida e inclusão no sentido atribuído por Pasche e Passos (2010). A construção de "soluções", ainda que provisórias e em permanente discussão, pauta-se pela inclusão como método de trabalho. A esse respeito, consideramos a seguinte indicação:

[...] o método da inclusão não propõe aderência ingênua e acrítica àquilo que o outro traz, mas aposta em uma atitude generosa, de acolher essas manifestações para, imediatamente, confrontá-la com a multiplicidade dos interesses do outro, do coletivo, para possibilitar a composição de contratualidades considerando orientações éticas. (PASCHE; PASSOS, 2010, p. 427)

Com efeito, a demanda trazida pela Cáritas para os professores da UERJ relacionava-se com a construção de Projeto PolíticoPedagógico para o curso de português que já era oferecido, com professores voluntários de variadas formações, usando apostilas fotocopiadas. Das reuniões com equipes de professores e de assistentes da Cáritas emergiram sentidos para o aprendizado da língua portuguesa, notadamente a partir dos relatos de experiências de refugiados residentes há mais tempo na cidade. Tornou-se óbvia a necessidade de acesso às políticas garantidoras de direitos sociais pelos refugiados por meio da língua, e foi a partir desta percepção que resolvemos elaborar material próprio, com o auxílio dos alunos do curso, professores voluntários e bolsistas do projeto.

Do ponto de vista da perspectiva adotada para a análise e intervenção pedagógicas, consideramos fundamental retomar dois eixos básicos da concepção bakhtiniana de língua (BAKHTIN, 2011). Propomos, a esse respeito, os seguintes princípios: i) todo enunciado é compreendido supondo sua relação dialógica com enunciados anteriores; ii) a compreensão de qualquer enunciado se dá pela produção de um novo enunciado. 
Desse modo, sem rejeitar um esforço de sistematização dos conhecimentos linguístico-gramaticais, o que nos parece fundamental desse tipo de compreensão sobre os fenômenos linguísticos reside justamente na premissa de que todo elemento linguístico remete a contextos concretos de enunciação, nos quais se encontram ancorados. Como direção conceitual do trabalho de supervisão, consideramos assim a importância de, sempre que possível, restituir os contextos interacionais dos quais os elementos em análise emergem.

Essa diretriz se encontra em consonância com o que vinha sendo discutido anteriormente. Nesses termos, a aprendizagem da língua é necessidade básica para se promover a inclusão dos refugiados na sociedade brasileira e, no caso específico, fluminense/carioca. $\mathrm{E}$ sendo necessidade básica, precisa garantir aos aprendizes-refugiados, que seus cotidianos sejam tomados como origem dos conteúdos a serem aprendidos. Não apenas os conteúdos dos cotidianos, mas também suas formas: os modos de falar, de tratar dos assuntos da vizinhança, da escola dos filhos, da busca pelo emprego, da circulação pela cidade. Também os conteúdos das culturas que são colocadas em convivência, a de origem e a do novo lugar de residência. Choques e proximidades culturais precisam ser ditos e problematizados, as diferentes maneiras de cuidar dos filhos, os diversos sentidos da escolarização, a diversidade da culinária, as diversas formas de compreender o mundo que são determinadas por histórias e culturas das sociedades de origem. A possibilidade, por exemplo, de conseguir os ingredientes daquele prato preferido que habita a mais alegre das memórias e pode, quem sabe, ser produzido, agora em território brasileiro, como em saudosos momentos que pareciam ter ficado definitivamente no passado.

Entendemos, conforme indicações já apresentadas em Arantes, Deusdará e Brenner (2016), a dimensão de intervenção institucional que tais questões potencializam; já a solicitação de trabalho que nos fora dirigida continha igualmente queixas acerca da insuficiência dos materiais didáticos disponíveis para as aulas e, por consequência, dos rituais, hábitos e crenças a respeito do ensino língua que contribuíam para cristalizar ou vinham sendo questionados.

No que diz respeito a esses impasses, pareceu-nos produtivo recuperar aqui parte dos debates que já registrarmos em torno das reflexões sobre a dinâmica em relação na qual fomos convidados a interagir. A respeito das queixas à perspectiva adotada pelo livro didático e o apagamento de um perfil específico de falante-refugiado, salientamos os seguintes aspectos:

[...] observamos que os professores praticavam um ensino prescritivo da língua portuguesa, baseado em uma progressão gramatical linear sugerida pelo livro didático que fora adotado. Nas falas dos professores voluntários, bem como no relato de alguns alunos, observou-se a necessidade expressa que os aprendizes apresentaram em querer se comunicar para resolver questões cotidianas, tais como: fazer compras, pegar ônibus ou preencher um formulário. Ademais, os alunos pareciam estabelecer um vínculo mais profícuo com os professores que lhes davam voz, que se mostravam interessados em conhecer seus hábitos de vida, suas motivações para a saída do país de origem, suas relações e estranhamentos com os hábitos brasileiros, dentre outros. (ARANTES; DEUSDARÁ, 2015, p. 48-49)

A título de ilustração da discussão que o fragmento anterior propõe, sugerimos a seguir um exemplo retirado de livro didático de ensino de língua portuguesa a refugiados. O referido exemplar parece ressaltar o tipo de trabalho com a língua que consideramos destacar. A língua é utilizada como ferramenta, como alguns manuais ainda insistem em fazê-lo: listas de palavras são destinadas à aprendizagem do vocabulário da lição, organizados de acordo com categorias elencadas a priori que não fazem sentido, conforme atestamos no arranjo abaixo: 


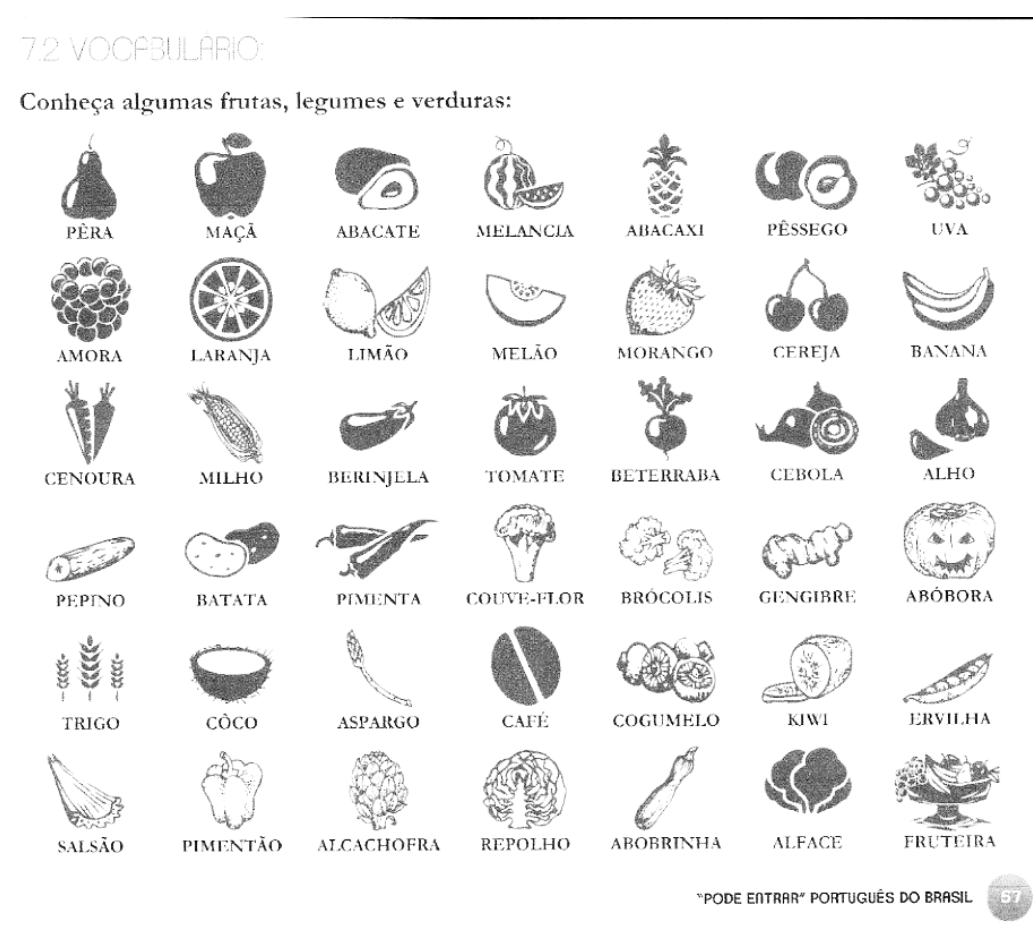

Figura 1: Vocabulário

Fonte: Feitosas et al. (2015)

Vemos que um inventário de verduras, legumes e frutas é apresentado aos alunos como input para a lição sobre "alimentação", sem qualquer menção ao contexto em que são utilizados e, ainda, apresentando objetos estranhos às categorias "verduras, legumes e frutas", como é o caso da "fruteira". Nossa experiência na supervisão da elaboração de materiais vem possibilitando observar que a menção a elementos que remetam a hábitos e formas de organização cotidiana - tais como culinária e outros usos cotidianos suscitam comentários, perguntas e relatos diversos em relação a vivências anteriores. Tais experiências autorizam indagações do seguinte tipo: qual a pertinência de se classificar esses elementos sem antes debater e discutir em que situações são utilizados? Como não antecipar questões que legitimem essas vivências anteriores?

Com isso, queremos indagar a necessidade de se aprender em torno de classificações por categoria, deslocadas do contexto, pois para quê um aprendiz de português precisa saber se o tomate é fruta ou legume, sem ter acesso ao modo como é utilizado na culinária da região? Nesse sentido, questionamos sobre como lidar com os impasses e limitações encontrados nas práticas de ensino de línguas com estrangeiros.

Outro aspecto que já mereceu considerações reside nos critérios que já vinham sendo adotados para a composição dos grupos de alunos no curso de Português para Refugiados. Considerando a diversidade linguística, os grupos de alunos foram distribuídos de acordo com a língua de mediação. Sobre essa questão, já destacamos o seguinte:

O critério de organização das turmas pareceu-nos bastante adequado, já que não se orientou por estereótipos recorrentes no universo escolar tradicional tais como faixa etária ou nível de escolaridade. Optou-se fundamentalmente por distribuir os diferentes grupos, elegendo-se línguas nativas ou de comunicação compartilhadas. O grupo estava então disposto em duas turmas de falantes nativos de francês, uma turma de falantes de espanhol e uma turma de falantes nativos ou estrangeiros em inglês. (ARANTES; DEUSDARÁ; BRENNER, 2016, p. 1203)

A partir dessas observações, consideramos que o ensino de língua portuguesa está estreitamente relacionado ao acesso a direitos, assim como todos os brasileiros e brasileiras possuem. É por esse motivo que o ensino deve se pautar nas necessidades e demandas desse grupo para o acesso a direitos e políticas públicas na cidade e no país como um todo. 
Ao lado dessa perspectiva acerca das implicações políticas da atuação profissional no contexto da acolhida a refugiados, a elaboração de uma proposta pedagógica também se debruçou sobre dificuldades específicas apresentadas pelo grupo: i) a intensa rotatividade dos alunos, visto que, ao chegar, os solicitantes de refúgio precisam ser imediatamente atendidos pelo curso e pelo serviço de assistência social da Cáritas-RJ; ii) assimilação das temáticas "emergenciais", considerando a insuficiência da caracterização excessivamente genérica do "estrangeiro" nos materiais disponíveis e a necessidade de incorporar e sustentar politicamente as angústias, impasses e desafios vivenciados no cotidiano dos refugiados; iii) a impossibilidade de sequenciamento linear, dada a recepção contínua de novos alunos e a diversidade de demandas apresentadas nos encontros frequentes de supervisão acadêmica das turmas.

Com efeito, acreditamos, portanto, num ensino de língua que não se baseie na imposição de conteúdos selecionados a priori por uma equipe de "especialistas" que dita quais conteúdos serão estudados e em que progressão, sobretudo porque no caso dos refugiados não é desejável que a primeira pergunta que se faça em sala seja “qual é o seu nome?" e “de onde você vem?”, como o é na maioria dos manuais para ensino de língua estrangeira. Dizer o nome e de onde vem representa, para esse grupo de alunos, um retorno à situação de perseguição que viveram em seus países e, eventualmente, a reprodução de determinados conflitos pela presença de refugiados na mesma sala oriundos dos diferentes grupos em conflito em seus países. Atesta-se, portanto, a necessidade de se conhecer as especificidades do grupo de aprendizes para pautarmos um ensino/aprendizagem de língua portuguesa não como língua estangeira, mas como "língua de acolhimento"2, que respeita as diferenças, que ouve as demandas e atua a partir delas e constrói seu planejamento horizontalmente, em contato direto com a população aprendiz da língua.

A construção horizontal nos permite questionar os marcadores de poder que há nas normatizações e prescrições de ensino de línguas estrangeiras, que consideram as palavras como ferramentas, muitas vezes associadas a esquemas de sinonímias que partem de uma visão estereotipada de arranjos.

As palavras não são ferramentas; mas damos às crianças linguagem, canetas e cadernos, assim como damos pás e picaretas aos operários. Uma regra de gramática é um marcador de poder, antes de ser um marcador sintático. A ordem não se relaciona com significações prévias, nem com uma organização prévia de unidades distintivas, mas sim o inverso. (DELEUZE; GUATTARI, 1997, p. 12)

Assim, levantamos, com os refugiados, situações cotidianas em que precisavam da língua portuguesa na cidade e chegamos à formulação de eixos temáticos orientadores da elaboração dos materiais. Tais eixos temáticos nortearam a elaboração de materiais que não seguem progressão gramatical linear e não são dependentes entre si.

A ideia da produção do material é que o professor possa utilizar quaisquer atividades produzidas em torno dos eixos temáticos, sem precisar respeitar ordem cronológica ou de progressão. Os conteúdos gramaticais, sintáticos e modalizadores se repetem, justamente porque o fluxo de alunos é contínuo, já que os refugiados são admitidos no curso assim que chegam ao Rio de Janeiro. Os conteúdos se repetem em variações temáticas: o uso do imperativo, por exemplo, é tematizado em uma lição sobre alimentação, em um exercício sobre receita de feijoada, e em uma lição sobre saúde, em uma prescrição médica.

Os conteúdos estruturais (verbo, substantivo, advérbio, modos e tempo verbais, etc...) não ocupam o centro das atividades, mas sim os temas e a produção oral em torno das situações de interação inseridas em seus contextos: na padaria, comprando um bilhete de transporte público, buscando emprego em um classificado e se apresentando em uma entrevista de emprego, preenchendo um formulário, etc.

O eixo temático sobre mobilidade urbana teve como objetivo facilitar o acesso à rede de transportes públicos pelos refugiados no estado do Rio de Janeiro. Desse modo, o uso de mapas de linhas de metrô, de trem e de ônibus foram os materiais de input utilizados. A partir deles, formulamos diálogos e situações cotidianas com as quais os refugiados tiveram contato e, posteriormente, eles

\footnotetext{
${ }^{2}$ A respeito do conceito “Língua de Acolhimento", ver Grosso (2010).
} 
próprios produziram seus diálogos simulando situações cotidianas de compra de bilhetes, busca de informações sobre transporte público em sua região de moradia (por meio dos mapas, leitura de placas, perguntas a pessoas na rua), etc.

Esse tipo de produção semiestruturada tem tido uma boa aceitação nas turmas, sobretudo porque, em muitos momentos, os alunos acabam se recordando de situações pelas quais passaram e tiveram dúvidas sobre como agir, como procurar e o que perguntar, e produzem seus conteúdos orais a partir dessa motivação. Como o tema da mobilidade tem adesão de todos, pois são usuários do transporte público cotidianamente, a motivação por entender mais sobre o funcionamento, sobre as possibilidades de se locomover por toda a cidade e ter acesso a bens culturais é ampliada.

O acesso aos transportes públicos garante o direito de ocupar os espaços das cidades que, muitas vezes, apresentam-se segregados, habitados apenas por sujeitos de determinadas classes, etnias e gêneros. Entendemos, portanto, que possibilitar o acesso dessa população de refugiados a zonas de produção cultural, praças, praias e espaços de arte é também produzir integração, dando a estes novos habitantes da cidade as condições de produzir novas referências e subjetividades em busca de uma igualmente nova cidadania no lugar de refúgio.

\section{CONSIDERAÇÕES FINAIS}

As discussões encaminhadas no presente artigo nos levam a (re)pensar a inclusão de refugiados em perspectiva democrática e promotora de direitos: direito à educação, à saúde, ao emprego, à mobilidade urbana, à ocupação de espaços públicos, dentre outros.

Essa perspectiva problematiza o modo desigual como tem sido concebida a população de refugiados no Brasil, sobretudo por intermédio da grande mídia: população que necessita de caridade e compaixão. Essa visão, além de preconceituosa, não considera o sujeito refugiado como protagonista desta história e não atribui a responsabilidade da acolhida a uma questão de ordem humanitária pois, afinal, as causas do refúgio não são debatidas e muito menos combatidas (em alguns casos, até incentivada por grandes potências).

Essa visão hierárquica do assistencialismo acaba por instaurar um cenário de piedade social que parece funcionar como mola propulsora para tranquilizar a "boa" consciência social, que se empenha em combater as desigualdades sociais geradas pela migração forçada. No entanto, esse tipo de prática não vem contribuindo para a acolhida; pelo contrário, ela desconsidera o outro como igual, como portador de direitos tanto quanto não refugiados. Essas questões, portanto, não podem deixar de ser problematizadas em sala de aula, sobretudo para que os refugiados possam ocupar espaços não somente como sujeitos aprendizes, mas como aprendizes com direitos. Talvez não seja demais lembrar: "Eu acredito que o que acontece no Congo não é um problema só do Congo, é um problema de todo mundo".

Para cumprir com esse objetivo que nos é muito caro à metodologia de ensino com refugiados que temos desenvolvido, procedemos à inversão teoria-método-análise, investindo no campo da micropolítica como forma de nos "desterritorializarmos" de modos e práticas comumente utilizados no ensino de línguas e que, infelizmente, vem sendo repetido sistematicamente com pouca reflexão e análise de demandas deficitária.

O presente trabalho esboça nosso esforço em tratar a aprendizagem e ensino de língua portuguesa a refugiados como área que merece atenção especial ao atendimento de demandas e promoção de acesso a direitos humanos. 


\section{REFERÊNCIAS}

ACNUR. Global Trends Forced Displacement 2016. Disponível em: <http://www.unhcr.org/globaltrends2017/>. Acesso em: 10 set. 2017.

AGAMBEN, G. Homo sacer: o poder soberano e a vida nua I. Trad. de Henrique Burigo. Belo Horizonte: Ed. da UFMG, 2002.

APÓS fechamento de campo em Calais, crianças refugiadas ficam sem abrigo. Folha de S. Paulo, São Paulo, 27 out. 2016. Mundo. Disponível em: shttps://wwwl.folha.uol.com.br/mundo/2016/10/1826791-apos-fechamento-de-campo-em-calais-criancasrefugiadas-ficam-sem-abrigo.shtml>. Acesso em: 13 set. 2017.

ARANTES, P. C. C.; DEUSDARA, B.; BRENNER, A. K. . Língua e alteridade na acolhida a refugiados: por uma micropolítica da linguagem. Fórum Linguístico (Online), v. 13, p. 1196-1207, $2016 . \quad$ Disponível em: <https://periodicos.ufsc.br/index.php/forum/article/view/1984-8412.2016v13n2p1196>. Acesso em: 8 out. 2017.

ARANTES, P. C. C.; DEUSDARA, B. Português para refugiados: aliando pragmática e discurso em resposta a uma demanda concreta. Letrônica, $\quad$ v. $\quad 8, \quad$ p. $45-59, \quad 2015 . \quad$ Disponível em: <http://revistaseletronicas.pucrs.br/ojs/index.php/letronica/article/view/19621>. Acesso em: 6 out. 2017.

BAKHTIN, M. Estética da criação verbal. Trad. de Paulo Bezerra. 6. ed. São Paulo: Martins Fontes, 2011.

BRASIL. Constituição da República Federativa do Brasil. Brasília, DF: Senado Federal: Centro Gráfico, 1988.

BRASIL. Estatuto da criança e do adolescente. Lei federal no 8069, de 13 de julho de 1990. Rio de Janeiro: Imprensa Oficial, 2002.

BRASIL. Lei de Diretrizes e Bases da Educação Nacional. Lei nº 9.394/96, de 20 de dezembro de 1996.

BRASIL. Brasil abriga 8.863 refugiados de 79 nacionalidades. 2016. Disponível em: <http://www.brasil.gov.br/cidadania-ejustica/2016/05/brasil-abriga-8-863-refugiados-de-79-nacionalidades>. Acesso em: 12 set. 2017.

BUTLER, J. Quadros de guerra: quando a vida é passível de luto? Trad. de Sérgio Tadeu de Niemeyer Lamarão e Arnaldo Marques da Cunha. Rio de Janeiro: Civilização Brasileira, 2009.

DELEUZE, G.; GUATTARI, F. 20 de novembro de 1923 - Postulados da Linguística. In: Mil Platôs: capitalismo e esquizofrenia. Trad. de Peter Pál Pelbart e Janice Caiafa. São Paulo: 34, 1997. p. 11-59.

DUARTE, D. A. A supervisão enquanto dispositivo: narrativa docente do estágio profissional em psicologia do trabalho. Interface: comunicação, saúde, educação, v. $19, \quad$ n. $\quad 52, \quad$ p. $\quad 133-44, \quad 2015 . \quad$ Disponível em: <http://www.scielo.br/scielo.php?script=sci_arttext\&pid=S1414-32832015000100133>. Acesso em: 10 out. 2017.

DUCROT, O. Esboço de uma teoria polifônica da linguagem. In: O dizer e o dito. Rev. da trad. de Eduardo Guimarães. Campinas: Pontes, 1987. p. 161-218. 
FEITOSA, J. et al. Pode entrar: português do Brasil para refugiadas e refugiados. São Paulo: Edição dos autores, 2015. Disponível em: <http://www.acnur.org/portugues/wp-content/uploads/2018/02/Pode_Entrar_ACNUR-2015.pdf>.Acesso em: 01 out. 2017.

FERNANDES, C. Crise dos refugiados na Europa UOL, 6 jun. 2016. Disponível em: $<$ http://vestibular.brasilescola.uol.com.br/atualidades/crise-dos-refugiados-na-europa.htm>. Acesso em: 12 set. 2017.

FRANÇA começa a transferir 1.500 crianças e jovens do campo de Calais. Folha de S. Paulo, São Paulo, 02 nov. 2016. Mundo. Disponível em: <https://wwwl.folha.uol.com.br/mundo/2016/11/1828705-franca-comeca-a-transferir-1500-criancas-e-jovensdo-campo-de-calais.shtml>. Acesso em: 13 set. 2017.

GROSSO, M. J. dos R. Língua de acolhimento, língua de integração. Horizontes de Linguística Aplicada, v. 9, n.2, p. 61-77, 2010. Disponível

$\mathrm{em}:$ <https://www.academia.edu/6956350/L\%C3\%ADngua_de_acolhimento_1\%C3\%ADngua_de_integra\%C3\%A7\%C3\%A3o?auto= download >. Acesso em: 15 jan. 2018.

ONU. Convenção Relativa ao Estatuto dos Refugiados. Disponível em: $<\mathrm{http}$ //www.acnur.org/fileadmin/Documentos/portugues/BDL/Convencao_relativa_ao_Estatuto_dos_Refugiados.pdf >. Acesso em: 10 set. 2017.

PASCHE, D. F.; PASSOS, E. Inclusão como método de apoio para a produção de mudanças na saúde - aposta da Política de Humanização da Saúde. Saúde em Debate, v. 34, n. 86, p. 423-432, jul./set., 2010. Disponível em: <http://www.redalyc.org/pdf/4063/406341769003.pdf>. Acesso em: 10 set. 2017.

ROCHA, M. L. da; AGUIAR, K. F. Pesquisa-intervenção e a produção de novas análises. Psicologia, ciência e profissão. v. 23 , n, 4, p. 64-73, 2003. Disponível em: <http://www.scielo.br/pdf/pcp/v23n4/v23n4a10.pdf>. Acesso em: 10 set. 2017. 